ORIGINAL ARTICLE

\title{
Lung adenocarcinoma: Sustained subtyping with immunohistochemistry and EGFR, HER2 and KRAS mutational status
}

\author{
Vitor Sousa ${ }^{a, b, *}$, Carolina Rodrigues ${ }^{a}$, Maria Silva ${ }^{a}$, Ana Maria Alarcão ${ }^{a}$, Lina Carvalho ${ }^{a, b}$
}

a IAP-FMUC-Institute of Pathology, Faculty of Medicine, University of Coimbra, Coimbra, Portugal

b Pathology Institute, Coimbra University Hospital, Coimbra, Portugal

Received 18 March 2014; accepted 1 September 2014

Available online 11 March 2015

KEYWORDS
Lung;
EGFR;
KRAS;
HER2;
Immunohistochemistry;
Adenocarcinomas

* Corresponding author.
E-mail address: vitorsousa. patol@gmail.com (V. Sousa).

\begin{abstract}
Pulmonary adenocarcinomas are still in the process of achieving morphological, immunohistochemical and genetic standardization. The ATS/ERS/IASLC proposed classification for lung adenocarcinomas supports the value of the identification of histological patterns, specifically in biopsies.

Thirty pulmonary adenocarcinomas were subjected to immunohistochemical study (CK7, CK5, 6, 18, CK20, TTF1, CD56, HER2, EGFR and Ki-67), FISH and PCR followed by sequencing and fragment analysis for EGFR, HER2 and KRAS.

Solid pattern showed lower TTF1 and higher Ki-67 expression. TTF1 expression was higher in non-mucinous lepidic and micropapillary patterns when compared to acinar and solid and acinar, solid and mucinous respectively. Higher Ki67 expression was present in lepidic and solid patterns compared to mucinous. EGFR membranous staining had increasing expression from non-mucinous lepidic/BA pattern to solid pattern and micropapillary until acinar pattern. EGFR mutations, mainly in exon 19, were more frequent in females, together with non-smoking status, while KRAS exon 2 mutations were statistically more frequent in males, especially in solid pattern. FISH EGFR copy was correlated gross, with mutations. HER2 copy number was raised in female tumours without mutations, in all cases. Although EGFR and KRAS mutations are generally considered mutually exclusive, in rare cases they can coexist as it happened in one of this series, and was represented in acinar pattern with rates of $42.9 \%$ and $17.9 \%$, respectively. EGFR mutations were more frequent in lepidic/BA and acinar patterns. Some cases showed different EGFR mutations.

The differences identified between the adenocarcinoma patterns reinforce the need to carefully identify the patterns present, with implications in diagnosis and in pathogenic understanding. EGFR and KRAS mutational status can be determined in biopsies representing bronchial
\end{abstract}


pulmonary carcinomas because when a mutation is present it is generally present in all the histological patterns.

(c) 2014 Sociedade Portuguesa de Pneumologia. Published by Elsevier España, S.L.U. All rights reserved.

\section{Introduction}

There are 1.3 million deaths from lung cancer annually worldwide and it is the leading cause of cancerrelated mortality in USA, Japan and Western-countries. ${ }^{1-4}$ Bronchial-pulmonary carcinomas were classified as small cell lung cancer (SCLC) and non-small cell lung cancer (NSCLC), representing $13 \%$ and $85 \%$ of lung cancers respectively. Squamous cell carcinoma (SQCC) and adenocarcinoma $(A D C)$ subdivision become mandatory due to personalized therapy and NSCLC designation should not be reported..$^{5,6}$

Bronchial-pulmonary adenocarcinomas are malignant epithelial tumours with glandular differentiation, and/or mucin production, acinar, papillary, micropapillary, bronchioloalveolar (BA)/lepidic, or solid with mucin growth patterns, complementing the morphological spectrum of mixed-type adenocarcinoma. The incidence differs with gender and population, being roughly $28 \%$ in men and $42 \%$ in women. Recently a new classification was proposed by ATS/ERS/IASLC. This new classification recognizes several patterns such as lepidic instead of BA, acinar, papillary, solid, and micropapillary. It also recognizes mucinous adenocarcinomas including the former mucinous BA carcinoma and colloid carcinoma. It also highlighted the need for an assertive diagnosis specially in biopsy material, supported by immunohistochemical study, with clinical, prognostic and therapeutic implications. ${ }^{5-8}$

The transmembrane tyrosine kinase epidermal growth factor receptor (EGFR) belonging to the EGFR family of receptor tyrosine kinases (TKs) called the HER or ErbB family (consisting of four members - EGFR (HER1/ErbB1), HER2 (ErbB2), HER3 (ErbB3) and HER4 (ErbB4) ) 9,10 may be overexpressed and this correlates with poor prognosis, with aggressive disease and decreased survival. ${ }^{3,11-14}$

KRAS mutations are associated with poor prognosis, reported since 1990, occurring in codon 12, occasionally at codon 13 and rarely at codon $61 .^{10,15,16}$ According to the current data, EGFR and KRAS mutations are mutually exclusive $10,17,18$; the explanation is related to KRAS-MAPK pathway inserts in the downstream signalling pathway of EGF. ${ }^{10}$ This mutation appears in $30 \%$ of Caucasian patients with lung cancer and $10 \%$ of East Asian adenocarcinomas. ${ }^{16,18,19}$ KRAS mutations are more frequent in smokers and are related to poor prognosis. ${ }^{10,16,17}$ Lung cancers with KRAS mutations are resistant to EGFR-TKIs and Yatabe confirmed in his study that none of the lung cancers with KRAS mutation achieved clinical response. ${ }^{10,20}$

Due to what has been said, the EGFR-MAPK signal transduction pathway is important to understand the role of individual somatic changes in tumours, predicting the response to EGFR-TKIs. EGFR status is then a favourable predictive factor in the case of sensitizing mutations. Despite the positive response observed in up to $70 \%$ of patients, different data concluded that not every patient benefitted from treatment with TKIs, probably due to mutations in the downstream effectors of EGFR signalling, more frequently KRAS gene. Mutations in this intermediate transduction pathway may also select patients; as KRAS acts downstream of EGFR receptor, its somatic changes can lead to a non-response to EGFR-TKIs as response rate to antiEGFR therapy is less than $3 \%$ in patients with KRAS mutant tumours as opposed to $20 \%$ in NSCLC with wild-type KRAS.

The objectives of this work are to evaluate EGFR and KRAS mutational status, EGFR and HER2 gene copy number and immunohistochemical EGFR and HER2 expression in lung adenocarcinomas according to the patterns/subtypes present, in order to understand the value of pattern recognition, supported by an immunohistochemical set used in routine, in adenocarcinoma diagnosis and anti-EGFR therapy decision.

\section{Materials and methods}

\section{Materials}

A series of 30 bronchial-pulmonary adenocarcinomas classified according with WHO 2004 histological classification and the new ATS/ERS/IASLC classification were selected from the archive of the Pathology Service of Coimbra University Hospital.

The patterns present were registered (namely lepidic/BA, acinar, papillary, micropapillary, solid and mucinous). Metastases were also registered by patterns. Clinical data like age, gender, smoking habits and stage were also registered.

\section{Ethical standards}

The principles of Helsinki Declaration were respected and the study was developed according to the Faculty of Medicine of the University of Coimbra.

Ethical Committee rules for PhD theses were followed.

\section{Immunohistochemistry (IHC)}

Representative sections of the adenocarcinomas and their patterns were submitted to IHC (CK7, TTF1, CK5/6, CD56 and CK20) to validate the pure condition of bronchial-pulmonary adenocarcinomas mainly to validate solid pattern. Ki67-MIB1 antibody was used to characterize proliferation index. C-erbB-1/EGFR and c-erbB-2/HER2 were applied to evaluate protein expression of these 
molecules. Endogenous peroxidase activity was quenched using $15 \mathrm{~min}$ incubation in $3 \%$ diluted hydrogen peroxide $\left(\mathrm{H}_{2} \mathrm{O}_{2}\right)$. For blocking nonspecific binding with primary antibodies we used Ultra V Block (Ultra Vision Kit; TP-125-UB; Lab Vision Corporation; Fremont CA; USA). Primary antibodies against CK7 (clone OV-TL12/30; DakoCytomation, Glostrup, Denmark) at a dilution of $1 / 50$ for $30 \mathrm{~min}$, Cytokeratin 5,6,18 (clone LP34; Novocastra Laboratories Ltd, Newcastle, United Kingdom) at a dilution of 1/100 for $60 \mathrm{~min}$, TTF1 (clone 8G7G3/1; DakoCytomation, Glostrup, Denmark) at a dilution of $1 / 100$ for $60 \mathrm{~min}$, CD56 (clone CD564; Novocastra Laboratories Ltd, Newcastle, United Kingdom) at a dilution of 1:75 for $60 \mathrm{~min}$, CK20 (clone KS20.8; DakoCytomation, Glostrup, Denmark) at a dilution of $1 / 50$ for $30 \mathrm{~min}$, Ki67 (clone MIB-1; DakoCytomation, Glostrup, Denmark) at a dilution of $1 / 50$ for $30 \mathrm{~min}$, cerbB-2 (Polyclonal; DakoCytomation, Glostrup, Denmark) at a dilution of $1 / 200$ for $30 \mathrm{~min}$, and c-erB-1 (clone 31G7; Invitrogen, Camarillo, California, USA) at a dilution of 1:20 for $30 \mathrm{~min}$ were applied to the cells and incubated at room temperature. They were washed with phosphate-buffered saline (PBS) (Ultra Vision; TP-125-PB; Lab Vision Corporation; Fremont CA; USA); and after this, for $15 \mathrm{~min}$, slides were incubated with biotin-labelled secondary antibody (Ultra Vision Kit; TP-125-BN; Lab Vision Corporation; Fremont (A; USA). Primary antibody binding was localized in tissues using peroxidase-conjugated streptavidin (Ultra Vision Kit; TP-125-HR; Lab Vision Corporation; Fremont CA; USA) and 3,3-diaminobenzidine tetrahydrochloride (DAB) (RE7190-K; Novocastra Laboratories Ltd, Newcastle, United Kingdom) was used as chromogen, according to manufacturer's instructions. Pretreatment was done with Pronase, $10^{\prime}$ for CK7, CK5,6,18, CK20 and c-erbB-1, with MW -micro wave, PH6, 20' for Ki67 and c-erbB-2 and with MW, EDTA, 40 ' for TTF1 and CD56. Haematoxylin was used to counterstain the slides which were then dehydrated and mounted. In parallel, known positive and negative controls were used.

The intensity of the staining was graded semiquantitatively on a four point scale $(0 ; 1+, 2+, 3+)$. The percentage of immunostained cells was also registered. A final score was obtained multiplying the intensity by the percentage of cells with immunohistochemical expression and the cut off considered was $10 \%$ positive cells.

\section{Fluorescent in situ hybridization - FISH}

The Vysis LSI EGFR/CEP7 probe assay (Vysis; Abbott Molecular, USA) was applied to tumour sections of $4 \mu \mathrm{m}$ thickness, baked overnight at $56^{\circ} \mathrm{C}$, deparaffinized in xylol, rehydrated in $100 \%, 70 \%$ ethanol and bidistilled water. A pressure cooker with $10 \mathrm{mM}$ citric acid-trisodium salt buffer $\mathrm{pH} 6$, for $4 \mathrm{~min}$, was used to submit slides to a pre-treatment. They were washed in $2 \times$ SSC salts (sodium chloride and sodium citrate) $\mathrm{pH} 7$ for $5 \mathrm{~min}$ at room temperature. At $15 \mathrm{~min}$ slides were immersed in proteinase $\mathrm{K}$ solution at $37^{\circ} \mathrm{C}$ and then, they were rinsed in $2 \times$ SSC $\mathrm{pH} 7$ for $5 \mathrm{~min}$ at room temperature. The slides were then dehydrated in $70 \%, 90 \%$ and $100 \%$ ethanol, and then air dried. Ten microliters of probe mixture were applied on the target areas and a $22 \mathrm{~mm} \times 22 \mathrm{~mm}$ glass coverslip was placed over probe.

After being sealed with rubber cement and codenaturation at $83^{\circ} \mathrm{C}$ for $5 \mathrm{~min}$, coverslips were incubated overnight at $37^{\circ} \mathrm{C}$ in a humidity chamber. Post-hybridization they had washes in buffer (50\% formamide $2 \times \mathrm{SCC} \mathrm{pH} 7)$ at $46^{\circ} \mathrm{C}$ and were also washed with $2 \times$ SCC pH 7. Slides were air-dried in the dark and counterstained with DAPI.

FISH was used to analyze the chromosome 7 and EGFR gene, and they were scored according to Cappuzzo's (2005) method. Positive FISH cases showed high polysomy or amplification and the same procedure was followed to HER2 probe (HER-2/Neu (17q12)/SE17; Kreatech diagnostics; Amsterdam). Positive and negative FISH cases were according to Varella-Garcia et al. ${ }^{21}$

The microscopic analyses were done in a Nikon Eclipse $80 \mathrm{i}$ of brilliant field and epifluorescent microscope (LUCIA cytogenetics software). Images were captured and registered with a digital camera (Nikon DXM 1220F), in monochromatic images/layers posterior joint in one single image. This process was assisted by Nikon ACT-1 capture software.

Overlapping cells were excluded from analysis. Two signals were counted as adjacent or fused only if they were separated by less than one domain. Two different individuals examined one hundred spindle cells interphase nuclei with strong and well-delineated signals.

Fluorescent signals were observed and quantified with a score previously defined using DAPI, FITC, Texas Red (unique band) and triple band (DAPI, FITC and Texas Red) filters.

\section{PCR, sequencing and fragment analysis}

Genomic DNA was extracted from $5 \mu \mathrm{m}$ section of paraffinembedded tissue after manual microdissection of all independent patterns separation as supported in Table 1. For that, the QIAmp DNA Mini Kit (Qiagen, IZAZA, Germany), was used. One hundred nanograms (ng) of DNA were amplified in a $50 \mu$ l reaction solution containing $5 \mu$ l of $10 \times$ buffer (Roche, Germany), $2.5 \mathrm{mM} \mathrm{MgCl} 2,0.2 \mu \mathrm{M}$ of each complementary primer, $200 \mu \mathrm{M}$ deoxynucleoside triphosphate and one unit of DNA polymerase (Roche, Germany). A $5 \mathrm{~min}$ initial denaturation at $95^{\circ} \mathrm{C}$ was used to perform the amplifications; this was followed by 40 cycles, $30 \mathrm{~s}$ at $95^{\circ} \mathrm{C}, 1 \mathrm{~min}$ at $60^{\circ} \mathrm{C}$ (for exon 19) or $57^{\circ} \mathrm{C}$ (for exon 21), 1 min at $72^{\circ} \mathrm{C}$ and $10 \mathrm{~min}$ of final extension at $72^{\circ} \mathrm{C}$.

The EGFR gene mutations located at exons 19 and 21 were determined using the intron-based primers according to the published method. ${ }^{22}$ Mutational analysis of exon 19 deletion L858R point mutation of the EGFR gene was explored, as described. ${ }^{23}$ The determination of exon 19 deletion was made by common fragment analysis using PCR with an FAMlabelled primer set, and the products were electrophoresed on ABI PRISM 3100 (Applied Biosystems ${ }^{\circledR}$ ) and all eletropherograms were reanalyzed by visual inspection in order to check for mutations. To evaluate the L858R mutation MyCycler (Bio-Rad) was also used and its products were then studied by direct sequencing.

The same procedure was applied to KRAS except for amplification, which we performed using a $5 \mathrm{~min}$ initial denaturation at $95^{\circ} \mathrm{C}$, followed by 40 cycles, $30 \mathrm{~s}$ at $95^{\circ} \mathrm{C}$, 
Table 1 Clinical and pathological characteristics of adenocarcinomas.

\begin{tabular}{|c|c|c|c|c|c|c|c|c|c|}
\hline Case & Gender & Age & Smoking habits & TNM & lassif & ation & Stage & Histologic patterns & Metastasis \\
\hline 1 & M & 73 & Non-smoker & $\mathrm{T} 1 \mathrm{a}$ & NO & $M x$ & IA & Acinar, Lepidic/BA & \\
\hline 2 & $\mathrm{~F}$ & 71 & Non-smoker & $\mathrm{T} 1 \mathrm{a}$ & NO & $M x$ & IA & Lepidic/BA, Acinar & \\
\hline 3 & M & 69 & Smoker & $\mathrm{T} 4$ & NO & $M X$ & IIIA & $\begin{array}{l}\text { Lepidic/BA, Acinar, } \\
\text { Papillary }\end{array}$ & \\
\hline 4 & M & 75 & Non-smoker & $\mathrm{T} 1 \mathrm{a}$ & N2 & $M x$ & IIIA & Acinar, Solid & Acinar, Solid \\
\hline 5 & $\mathrm{~F}$ & 53 & Non-smoker & T1a & NO & $M x$ & $\mathrm{IA}$ & Acinar, Lepidic/BA & \\
\hline 6 & $\mathrm{~F}$ & 62 & Ex-smoker & $\mathrm{T} 1 \mathrm{a}$ & N2 & $M x$ & IIIA & Acinar, Solid & Acinar, Solid \\
\hline 7 & $\mathrm{~F}$ & 74 & Non-smoker & $\mathrm{T} 1 \mathrm{a}$ & NO & $M x$ & IB & Acinar, Solid, Lepidic/BA & \\
\hline 8 & $\mathrm{~F}$ & 68 & Non-smoker & $\mathrm{T} 2 \mathrm{a}$ & NO & $M x$ & IB & $\begin{array}{l}\text { Acinar, Solid, } \\
\text { Micropapillary Mucinous }\end{array}$ & \\
\hline 9 & $\mathrm{~F}$ & 50 & Non-smoker & $\mathrm{T} 1 \mathrm{~b}$ & N2 & $M x$ & IIIA & Acinar, Solid & Acinar \\
\hline 10 & $\mathrm{~F}$ & 57 & Smoker & $\mathrm{T} 2 \mathrm{a}$ & NO & $M x$ & IB & Acinar, Solid & \\
\hline 11 & M & 51 & Non-smoker & $\mathrm{T} 1 \mathrm{a}$ & $\mathrm{N} 1$ & $M x$ & IIA & Acinar, Lepidic/BA & Acinar. Solid \\
\hline 12 & $\mathrm{~F}$ & 75 & Non-smoker & $\mathrm{T} 2 \mathrm{a}$ & NO & $M x$ & IB & $\begin{array}{l}\text { Acinar, Solid, } \\
\text { Micropapillary }\end{array}$ & \\
\hline 13 & M & 85 & Ex-smoker & $\mathrm{T} 1 \mathrm{a}$ & NO & $M x$ & IA & $\begin{array}{l}\text { Acinar, Lepidic/BA } \\
\text { Papillary }\end{array}$ & \\
\hline 14 & $\mathrm{~F}$ & 63 & Smoker & $\mathrm{T} 1 \mathrm{a}$ & N2 & $M x$ & IB & $\begin{array}{l}\text { Acinar, Lepidic/BA } \\
\text { Micropapillary, Papillary }\end{array}$ & Acinar, Solid \\
\hline 15 & $\mathrm{~F}$ & 55 & Smoker & $\mathrm{T} 1 \mathrm{a}$ & NO & $M x$ & IA & Acinar, solid & \\
\hline 16 & $\mathrm{~F}$ & 67 & Smoker & T1a & NO & $M x$ & IA & $\begin{array}{l}\text { Lepidic/BA, Acinar, } \\
\text { Micropapillary }\end{array}$ & \\
\hline 17 & M & 48 & Smoker & $\mathrm{T} 1 \mathrm{a}$ & NO & $M x$ & IA & Acinar, Solid, Lepidic/BA & \\
\hline 18 & M & 71 & Non-smoker & $\mathrm{T} 2 \mathrm{a}$ & N1 & $M x$ & IIA & $\begin{array}{l}\text { Acinar, Papillay, } \\
\text { Micropapillary }\end{array}$ & Acinar \\
\hline 19 & $\mathrm{~F}$ & 80 & Non-smoker & $\mathrm{T} 1 \mathrm{~b}$ & NO & $M x$ & $\mathrm{IA}$ & Acinar, Micropapillary & \\
\hline 20 & $\mathrm{~F}$ & 68 & Non-smoker & $\mathrm{T} 2 \mathrm{a}$ & $\mathrm{N} 1$ & $M x$ & IIA & $\begin{array}{l}\text { Acinar, Lepidic/BA } \\
\text { Micropapillary }\end{array}$ & $\begin{array}{l}\text { Acinar, } \\
\text { Micropapillary }\end{array}$ \\
\hline 21 & M & 48 & Non-smoker & $\mathrm{T} 2 \mathrm{~b}$ & $\mathrm{~N} 1$ & $M X$ & IIA & Lepidic/BA, Acinar, & Acinar \\
\hline 22 & $\mathrm{~F}$ & 67 & Non-smoker & $\mathrm{T} 2 \mathrm{a}$ & NO & $M x$ & IB & Acinar, Mucinous & \\
\hline 23 & M & 76 & Ex-smoker & $\mathrm{T} 1 \mathrm{~b}$ & NO & $M x$ & IA & $\begin{array}{l}\text { Lepidic/BA, Acinar, } \\
\text { Mucinous }\end{array}$ & \\
\hline 24 & $\mathrm{~F}$ & 56 & Non-smoker & $\mathrm{T} 1 \mathrm{a}$ & NO & $M X$ & $\mathrm{IA}$ & $\begin{array}{l}\text { Lepidic/BA, Acinar, } \\
\text { Micropapillary, Papillary }\end{array}$ & \\
\hline 25 & M & 64 & Smoker & $\mathrm{T} 2 \mathrm{~b}$ & NO & $M x$ & IIA & Acinar, Papillary & \\
\hline 26 & $\mathrm{~F}$ & 71 & Non-smoker & $\mathrm{T} 2 \mathrm{a}$ & NO & $M X$ & IB & Lepidic/BA, Acinar, Solid & \\
\hline 27 & $\mathrm{~F}$ & 50 & Smoker & $\mathrm{T} 2 \mathrm{a}$ & NO & $M X$ & IB & Lepidic/BA, Solid & \\
\hline 28 & $\mathrm{~F}$ & 80 & Non-smoker & $\mathrm{T} 1 \mathrm{a}$ & NO & $M x$ & IA & Solid & \\
\hline 29 & M & 56 & Smoker & $\mathrm{T} 1 \mathrm{a}$ & NO & $M X$ & IA & Lepidic/BA, Acinar & \\
\hline 30 & $\mathrm{~F}$ & 56 & Non-smoker & $\mathrm{T} 1 \mathrm{a}$ & NO & $M x$ & $\mathrm{IA}$ & Lepidic/BA, Acinar & \\
\hline
\end{tabular}

$1 \mathrm{~min}$ at $53^{\circ} \mathrm{C}, 1 \mathrm{~min}$ at $72^{\circ} \mathrm{C}$ and a $10 \mathrm{~min}$ of final extension at $72^{\circ} \mathrm{C}$.

The same procedure was applied to HER2 except for amplification, which we performed using a $1 \mathrm{~min}$ initial denaturation at $95^{\circ} \mathrm{C}$; followed by 35 cycles, $30 \mathrm{~s}$ at $95^{\circ} \mathrm{C}$, $1 \mathrm{~min}$ at $64^{\circ} \mathrm{C}, 1 \mathrm{~min}$ at $72{ }^{\circ} \mathrm{C}$ and $10 \mathrm{~min}$ of final extension at $72{ }^{\circ} \mathrm{C}$.

\section{Statistical analyses}

PASW Statistics, version 18, to do the statistical analysis of the information was applied. To do the characterization of the sample we calculated mean and standard deviation for quantitative variables and we determined the absolute and relative frequencies for qualitative variables. We made several comparisons between nominal variables (gender, smoking habits, mutations) using Chi-square test, Fisher's Exact test and ANOVA. Immunohistochemistry, FISH and Mutational (PCR) results' concordances were calculated by kappa coefficient. Correlation coefficient $r$ was also calculated (Spearman test). The comparison between the existence of different types of mutation and age was realized with Mann-Whitney's test. A significance level of $5 \%$ $(p \leq 0.05)$ was considered.

\section{Results}

\section{Patterns and clinical data}

Table 1 shows 29 cases of mixed-type adenocarcinomas with registration of decreasing percentage of the identified 


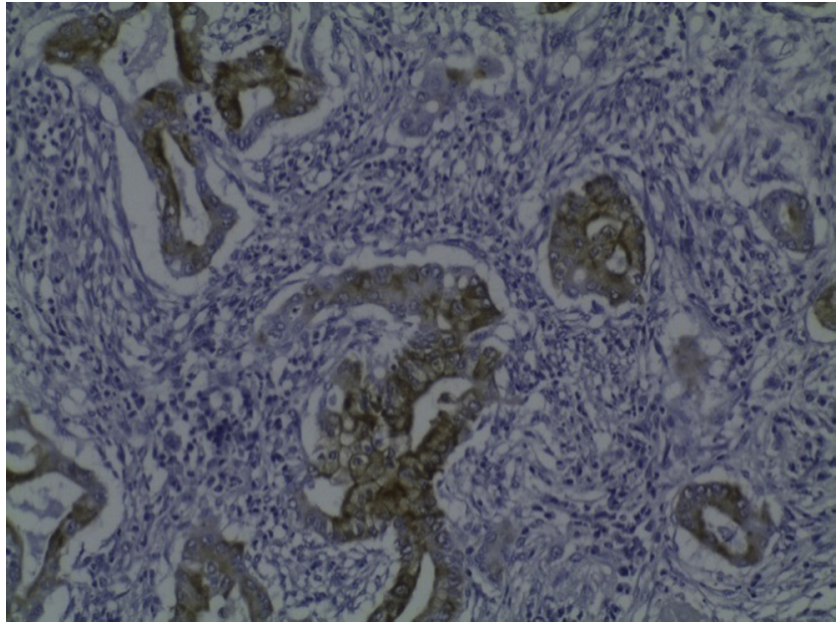

Figure 1 Case 21: 2+ CK20 expression; acinar pattern. 200×.

patterns: 28 (93.4\%) cases with acinar pattern, 18 (60\%) cases with non-mucinous lepidic/BA pattern, 12 (40\%) cases with solid pattern, $8(26.7 \%)$ cases with micropapillary pattern, $6(20 \%)$ cases with papillary pattern and $3(10 \%)$ cases with mucinous pattern. Case 28 was the only where only one pattern was present (solid pattern). Two patterns were represented in 16 cases (7 cases had acinar and lepidic/BA non-mucinous patterns, 5 cases had acinar and solid patterns, 1 case had acinar and papillary patterns, 1 case had acinar and micropapillary patterns, 1 case had acinar and mucinous glandular patterns and 1 case had lepidic/BA and solid patterns); 13 cases showed 3 or more histological patterns and of these, the most frequent association was acinar, lepidic/BA non-mucinous and solid patterns $(n=3)$, followed by acinar, lepidic/BA non-mucinous and micropapillary patterns $(n=2)$, acinar, lepidic/BA non-mucinous and papillary patterns $(n=2)$ and acinar, lepidic/BA non-mucinous, papillary and micropapillary patterns $(n=2)$.

In this series, 19 (63.3\%) cases belonged to female gender, $11(36.7 \%)$ cases to masculine gender, 18 (60\%) cases had no smoking habits, $9(30 \%)$ cases belonged to smoker patients and $3(10 \%)$ cases to ex-smoker patients (Table 1$)$; of 18 nonsmoking patients (admitting passive smoking), there were 13 females. It is important to notice that histological patterns present in lymph node metastasis belonged to acinar, solid and micropapillary morphology (pN1/2-8 cases).

\section{Immunohistochemistry}

All histological types and patterns identified were CK 5,6,18 and CD56 negative without statistical significant differences $(p>0.05)$. Normal epithelial basal cells were all positive for CK5,6,18 as internal control; lymph node metastasis did not express these antibodies.

As with normal parenchyma, equivalent results were seen after the application of CK20 except: in two cases of mixedtype adenocarcinoma, where acinar and lepidic/BA patterns had a $2+$ expression (moderate intensity) in $50 \%$ of the cells; in a third case, the mucinous glandular pattern had CK20 weak expression (1+) in $10 \%$ of the neoplastic cells (Fig. 1). These three cases expressed CK7 3+ and TTF1 3+ (Fig. 1). Lymph node metastasis had no CK20 expression.

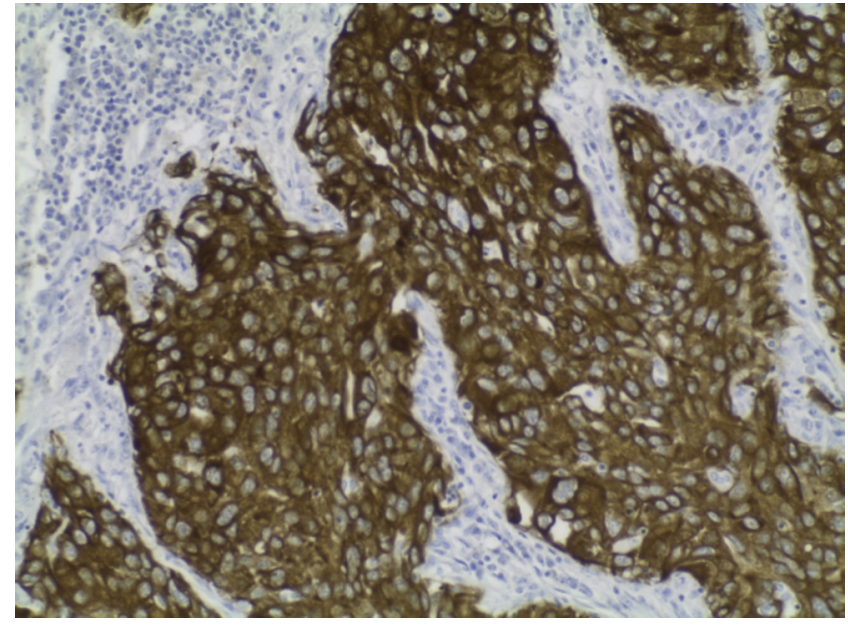

Figure 2 Case 6: CK7 intense expression (3+) in solid pattern. $200 \times$.

Mucinous pattern showed lower expression of CK7 than normal pulmonary epithelial cells and respiratory cylindrical epithelial cells $(p=0.09)$; acinar pattern $(p=0.0584)$, lepidic/BA pattern $(p=0.0822)$, micropapillary pattern $(p=0.086)$ and solid pattern $(p=0.0661)$ had higher expression of CK7 than mucinous glandular pattern (Fig. 2).

Considering mucinous pattern, one case had no CK7 expression; CK7 expression was moderately intense $(2+)$ in $50 \%$ of the cells in another case and a third case, had intense $(3+)$ expression in $80 \%$ of the cells.

TTF1 expression was positive in normal alveolar septae cells as expected; it was negative in 6 acinar pattern cases, in 2 of the non-mucinous lepidic/BA pattern cases, in 1 papillary pattern case and in 2 solid pattern cases. Overall expression, taking into account the intensity and the percentage of positive cells, for TTF1 higher expression was seen in lepidic/BA pattern $(p=0.002)$ and in micropapillary pattern $(p=0.005)$, when compared to normal alveolar septae. In mucinous patterns, expression was lower when compared to normal tissues $(p=0.0192)$. There were no differences between normal tissue and papillary pattern $(p=0.315)$ and lepidic/BA pattern had higher expression than acinar pattern $(p=0.059)$ and solid pattern $(p=0.0115)$. Micropapillary pattern had higher expression when compared to acinar $(p=0.0413)$, solid $(p=0.009)$ and mucinous $(p=0.0225)$ patterns.

Adenocarcinomas showed higher proliferative index, validated by Ki67 expression, than normal tissues $(p<0.05)$. Ki67 expression was also higher in lepidic/BA (non-mucinous) pattern when compared to mucinous pattern $(p=0.0845)$ and in solid compared to mucinous patterns $(p=0.0817)$. Basal cells in respiratory epithelium expressed Ki67 in 50\% of cells.

We did not find membrane staining/expression for CerbB2 in any cases of the studied adenocarcinomas. Cytoplasmatic expression was seen in all patterns and in normal tissues adjacent to the neoplasias, with significant statistical differences between alveolar septae and acinar patterns $(p<0.0001)$, lepidic/BA pattern $(p<0.0001)$, papillary pattern $(p=0.004)$, micropapillary pattern $(p<0.0001)$, solid pattern $(p=0.0006)$ and mucinous pattern $(p=0.0073)$. 


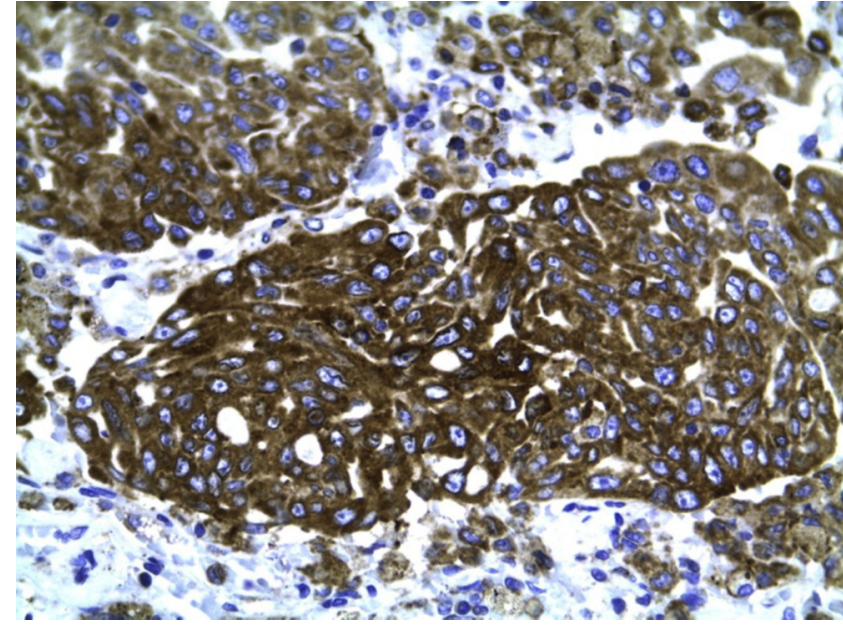

Figure 3 Case 7: ErbB-2 3+ cytoplasmatic expression; solid pattern. ErbB-2, 400×.

Solid pattern had lower expression than acinar $(p=0.0034)$, lepidic/BA $(p=0.004)$, papillary $(p=0.0334)$ and micropapillary patterns $(p=0.0089)$ (Figs. 3 and 4$)$.

EGFR membrane immunostaining was revealed in acinar pattern of 5 adenocarcinomas as moderate $(2+)$ and in 4 cases as intense (3+). We did not find membrane expression in papillary pattern. In micropapillary pattern, one case showed $2+$ membrane expression and 3 cases $3+$. Non-mucinous lepidic/BA pattern showed 2+ membrane expression in 2 cases and $3+$ in one case. Solid pattern showed 2 cases with $2+$ positivity and 3 cases with $3+$ membrane expressions. Mucinous pattern was negative in all studied adenocarcinomas.

Pulmonary parenchyma also expressed membranous EGFR in epithelial cells but at a very low rate when compared to adenocarcinomas $(p=0.0029)$. Higher expression was verified in solid pattern $(p=0.097)$ and in micropapillary pattern $(p=0.0457)$ when compared to lepidic/BA pattern (Fig. 5).

Considering immunohistochemical expression between primary adenocarcinomas patterns and lymph node

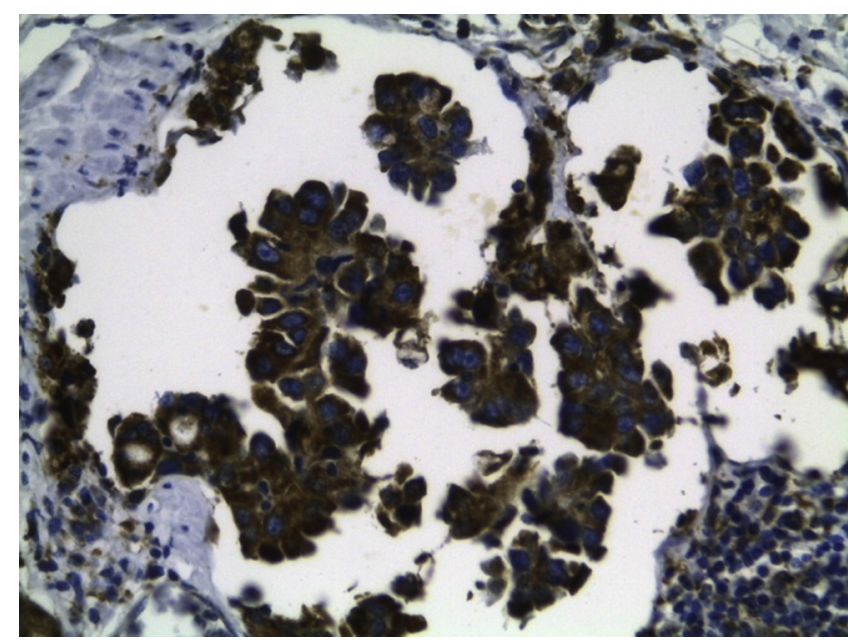

Figure 4 Case 8: ErbB-2 3+ cytoplasmatic expression; micropapillary pattern. ErbB-2, 400x.

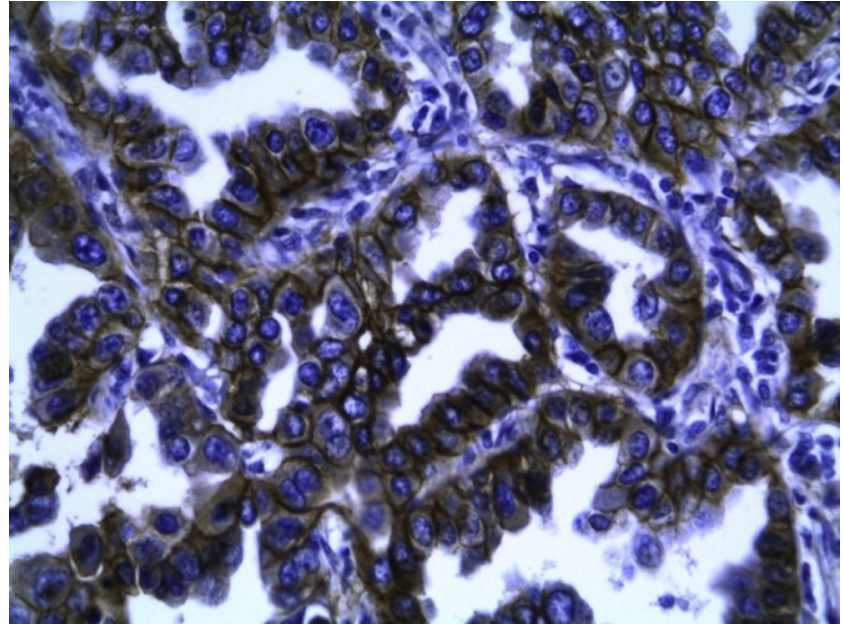

Figure 5 Case 12: Intense (3+) EGFR expression; acinar pattern. EGFR, 200×.

metastasis there was no statistical significance for CK7, CK20, CK 5,6,18, CD56, TTF1 and Ki67 proliferative index.

CerbB2 was not expressed as membrane staining in the metastatic (some cytoplasmatic expression was seen) malignant cells. There were no statistical significant differences between primitive patterns in adenocarcinomas and respective metastasis $(p=0.3711)$ for the cytoplasmatic stain previously described.

Taking into account membrane expression of EGFR there were no differences between the adenocarcinomas' patterns and the lymph node metastasis $(p=0.108)$.

\section{HER2, EGFR and KRAS mutational status}

\section{HER2 mutations}

HER2 exon 20 mutation was absent in 30 cases of adenocarcinomas. All the patterns were wild-type (WT).

\section{EGFR mutations}

EGFR exon 21 point mutation occurred in 8 cases of the 30 adenocarcinomas studied: in 6 cases, the mutation was present in all the patterns of the adenocarcinoma, in 2 cases the mutation was present in the acinar pattern and the other patterns were WT (lepidic/BA and solid and lepidic/BA patterns, respectively).

A group of 10 adenocarcinomas showed exon 19 deletions: 6 with mutations in all patterns; one case with mutation in lepidic/BA pattern and acinar pattern WT; the remaining 3 cases had mutations present in one pattern (namely two cases in acinar and one case in lepidic/BA patterns).

EGFR mutations were present in $42.9 \%$ of acinar pattern. EGFR mutations were more frequent in lepidic/BA and acinar patterns $(p=0.008)$.

Deletion of 9pb (DEL 9pb) was present in 5 cases, deletion $15 \mathrm{pb}$ (DEL 15pb) in 4 cases, DEL 18pb in 2 cases and DEL 12pb in one case.

One singular case showed 3 types of deletion, mainly DEL $19 \mathrm{pb}, 15 \mathrm{pb}$ and $18 \mathrm{pb}$ in the acinar pattern and DEL 15pb in solid and micropapillary patterns. 
Table 2 EGFR exon 19 mutations (n.p. - not present this pattern; n.d. - not determined).

\begin{tabular}{|c|c|c|c|c|c|}
\hline Case & Lepidic/BA & Acinar & Solid & Micropapillary & Mucinous \\
\hline 7 & n.d. & DEL 9 pb & n.d. & n.p. & n.p. \\
\hline 8 & n.p. & DEL $9,15,18 \mathrm{pb}$ & DEL $15 \mathrm{pb}$ & DEL 15 pb & n.d. \\
\hline 9 & n.p. & DEL 9 pb & n.d. & n.p. & n.p. \\
\hline 12 & n.p. & DEL $15 \mathrm{pb}$ & DEL $15 \mathrm{pb}$ & n.d. & n.p. \\
\hline 16 & DEL $12 \mathrm{pb}$ & DEL $12 \mathrm{pb}$ & n.p. & DEL $12 \mathrm{pb}$ & n.p. \\
\hline 19 & n.p. & DEL $15 \mathrm{pb}$ & n.p. & DEL $15 \mathrm{pb}$ & n.p. \\
\hline 20 & DEL 15 pb & DEL $15 \mathrm{pb}$ & n.p. & n.p. & n.p. \\
\hline 24 & DEL 9 pb & DEL 9 pb & n.p. & DEL 9 pb & n.p. \\
\hline 26 & DEL $18 \mathrm{pb}$ & n.d. & n.p. & n.p. & n.p. \\
\hline 30 & DEL 9 pb & WT & n.p. & n.p. & n.p. \\
\hline
\end{tabular}

Table 3 EGFR exon 21 mutations (n.p. - not present in pattern; n.d. - not determined).

\begin{tabular}{rllllll}
\hline Case & Lepidic/BA & Acinar & Papillary & Solid & Micropapillary & Mucinous \\
\hline 1 & L858R & L858R & n.p. & n.p. & n.p. & n.p. \\
7 & n.d. & L858R & n.p. & n.d. & n.p. & n.p. \\
14 & n.d. & L858R & L858R & n.p. & n.d. & n.p. \\
18 & n.p. & L858R & L858R & n.p. & n.d. & n.d. \\
23 & L858R & L858R & n.p. & n.p. & n.p. & n.p. \\
24 & L858R & L858R & n.d. & n.p. & L858R & n.p. \\
26 & WT & L858R & n.p. & WT & n.p. & n.p. \\
30 & WT & L858R & n.p. & n.p. & & \\
\hline
\end{tabular}

In 4 adenocarcinomas, coexisting L858R exon 21 point mutations and exon 19 deletions were seen. In two of these cases the L858R and Del9pb mutations were present in all patterns (acinar, lepidic/BA and solid patterns in one case and in acinar pattern in another case). In one case, L858R exon 21 point mutation was seen in acinar pattern and exon 19 deletion (DEL 18pb) in lepidic/BA pattern. In another case exon 19 deletion (DEL 9pb) in lepidic/BA pattern and L858R exon 21 point mutation in acinar pattern were observed. Tables 2 and 3 explain the obtained mutational status.

The obtained results showed that for EGFR, exon 19 mutations were present in the different histological patterns of the same tumour. In cases 8 and 30, lepidic/BA, acinar, solid and micropapillary patterns expressed different mutations: in case 8 , solid and micropapillary patterns only expressed DEL 15pb, acinar pattern also expressed DEL 9pb and DEL 18pb simultaneously and case 30 expressed differences between lepidic/BA and acinar patterns, as the first one expressed DEL 9pb and the second one was WT.

In case 26 , lepidic/BA pattern had DEL 18pb while the acinar pattern was undetermined.

After applying the Mann-Whitney test, patient's age was not statistically related with the existence of EGFR mutations (neither EGFR-Exon 19 nor EGFR-Exon 21 mutations) with $p=0.156$. EGFR mutations were more frequent in female patients $(p=0.004)$.

There was a statistical relationship between EGFR mutations and female gender $(p=0.001)$ (Chi-Square Tests). The estimated risk obtained Odds ratio for sex $=6.286$ (95\% confidence interval between 1.918 and 20.603) for females.

\section{KRAS mutations}

Of the 30 adenocarcinomas studied 5 cases had exon 2 point mutations, 3 of them of the type G12 V (Valine) and 2 of the type G12C (Cystein).

For the cases with KRAS mutation, 4 had no EGFR mutations with the exception of one case that had also exon 21 EGFR mutation and these mutations were present in the two patterns (lepidic/BA and acinar) of this mixed-type adenocarcinoma.

In relation to KRAS exon 2 wild type, the mean age was 66.35 years with a 95\% Confidence Interval for mean between 64.12 and 68.59 years, with a minimum of 50 and a maximum of 80 years; for KRAS exon 2 mutated, the mean age was 62.60 years with a $95 \%$ Confidence Interval for mean between 51.16 and 74.04 years and with a minimum of 48 and a maximum of 85 years. After applying the Mann-Whitney test, no statistical relevance was found between the relation of KRAS-exon 2 and the age of the individuals (for WT and mutated) as $p=0.401$ (Table 4).

KRAS mutations were statistically related with male gen$\operatorname{der}(p=0.001)$. (Fisher's Exact Test).

The relationship between smoking habits and KRAS mutations was statistically relevant $(p=0.014)$ with higher incidence in smokers.

\section{EGFR and HER2 copy number - FISH}

For EGFR copy number, 12 FISH positive cases (either high polysomy or amplification) (Figs. 6 and 7) and 18 FISH negative cases were demonstrated. The positive cases showed 
Table 4 KRAS exon 2 mutations (n.p. - not present in this pattern; n.d. - not determined).

\begin{tabular}{llllll}
\hline Case & Lepidic/BA & Acinar & Papillary & Solid & Mucinous \\
\hline 13 & n.d. & G12C & G12C & n.p. & n.p. \\
17 & n.d. & G12V & n.p. & G12V & n.p. \\
21 & G12V & G12V & n.p. & n.p. & n.d. \\
23 & G12V & G12V & n.p. & & \\
& $(E G F R$ & (EGFR & & n.p. \\
\hline
\end{tabular}

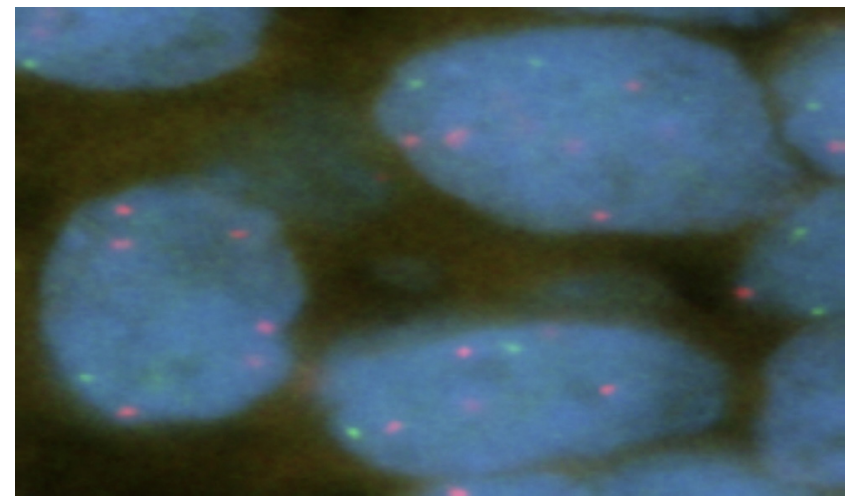

Figure 6 Case 7: FISH positive for EGFR/chromosome 7 centromere. Gene high polysomy; EGFR - red signal, chromosome 7-green. $1000 \times$.

positivity in all the patterns present. In the $12 \mathrm{FISH}$ positive cases, 3 were EGFR WT and 9 had EGFR mutations. On the other hand, of the 18 FISH negative cases, 13 were EGFR WT and 5 had EGFR mutations with concordance $\mathrm{K}$ Test of $k=0.4595$ (moderate agreement). These results were consistent in all patterns of each tumour.

When considering the $\mathrm{K}$ Test for concordance between FISH results and each mutational type (exons 21 and 19) the concordance was only considered as fair $(k=0.2857$ and $k=0.2647$, respectively).

The concordance ( $\mathrm{K}$ Test) between mutational status and EGFR immunohistochemical expression (positive/negative) was considered fair $(k=0.2556)$. The concordance ( $K$ test)

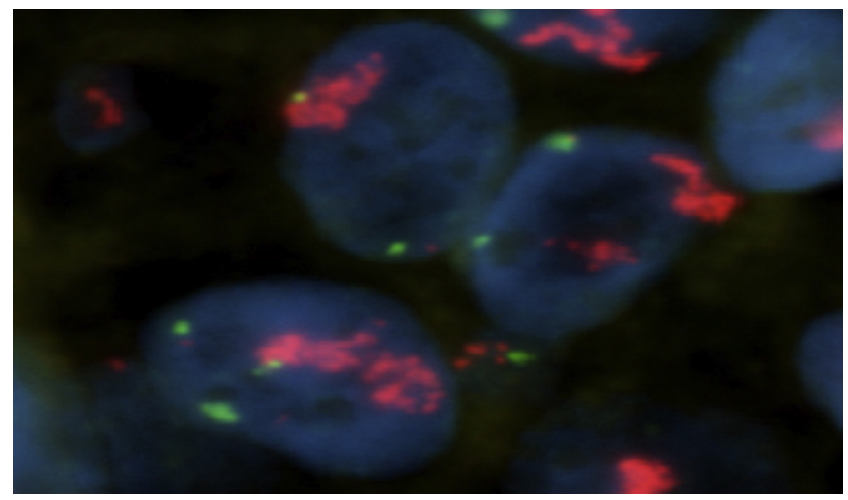

Figure 7 Case 12: EGFR/chromosome 7. Gene amplification; FISH positive. EGFR/chromosome 7 centromere. EGFR - red signal, chromosome 7-green. $1000 \times$. between FISH status and IHC results were also considered as fair $(k=0.2635)$.

Correlation coefficient between immunohistochemical EGFR expression and mutational status was considered not quite significant $(p=0.0561)$ with $r=0.3525$. Correlation coefficient between EGFR mutational status and FISH status $(r=0.5303)$ was considered very significant $(p=0.0026)$. No correlation was identified between EGFR protein expression and FISH status.

HER-2 FISH positive (mainly by polysomy) cases were identified in 10 cases corresponding mainly to women and 20 cases were HER-2 FISH negative (Table 5 concise HER2 and EGFR positive cases). It was relevant that FISH negative adenocarcinomas had also FISH negative lymph node metastasis. In FISH positive adenocarcinomas, where lymph nodes metastases were present, they were HER2 FISH negative.

\section{Discussion}

The predictive importance of making accurate and more specific diagnosis of bronchial-pulmonary carcinoma, in biopsies, especially differentiating adenocarcinomas from squamous cell carcinoma and other histological types was searched by applying a panel of antibodies (CK7, TTF1, CK 5,6,18, CK20 and CD56) to establish the diagnosis of primary adenocarcinomas towards other pulmonary histological types and metastatic adenocarcinomas, following the proposed classification for lung adenocarcinomas. ${ }^{8} \mathrm{IHC}$ was made to validate the pure condition of bronchialpulmonary adenocarcinomas mainly to validate solid pattern and establish differential diagnosis, as well as characterize proliferation index (Ki67-MIB1 antibody). We tried also to identify differences of expression between the patterns studied in order to understand and validate the importance of differentiating patterns. All morphological patterns were registered for each adenocarcinoma and revealed negativity for CK5,6,18 and for CD56, excluding squamous and neuroendocrine differentiations, as shown by other authors. ${ }^{24-26}$ CD56 is useful for excluding neuroendocrine differentiation, thus confirming that we are dealing with pure adenocarcinomas, not combined adenocarcinomas.

High importance has been given to CKs family, formed by more than 30 polypeptides, distributed by tissue and differentiation-specific weights, allowing phenotyping by combining particularly CK7, CK20 and epidermoid/basal cells high weight CKs to determine origin of cell types or tissue. ${ }^{25-32}$ 
Table 5 EGFR and HER2 FISH Positive Results.

\begin{tabular}{|c|c|c|c|c|c|}
\hline Case & Pattern & EGFR & Estrat & HER2 & Estrat \\
\hline \multirow[t]{2}{*}{11} & Lepidic/BA & Pos & $\mathrm{HP}$ & Neg & Dis \\
\hline & Acinar & Pos & $\mathrm{HP}$ & Neg & Dis \\
\hline \multirow[t]{3}{*}{333} & Papillary & Pos & $\mathrm{HP}$ & Pos & $\mathrm{HP}$ \\
\hline & Lepidic/BA & Neg & LP & Pos & $\mathrm{HP}$ \\
\hline & Acinar & Pos & $\mathrm{HP}$ & Pos & $\mathrm{HP}$ \\
\hline \multirow[t]{2}{*}{66} & Solid & Pos & $\mathrm{HP}$ & Pos & $\mathrm{HP}$ \\
\hline & Acinar & n.d. & n.d. & n.d. & n.d. \\
\hline \multirow[t]{3}{*}{777} & Solid & Pos & $\mathrm{HP}$ & Pos & $\mathrm{HP}$ \\
\hline & Acinar & Pos & $\mathrm{HP}$ & Pos & $\mathrm{HP}$ \\
\hline & Lepidic/BA & n.d. & n.d. & n.d. & n.d. \\
\hline \multirow[t]{4}{*}{8888} & Acinar & Pos & $\mathrm{HP}$ & Pos & $\mathrm{HP}$ \\
\hline & Solid & Pos & $\mathrm{HP}$ & Neg & $\mathrm{BP}$ \\
\hline & Micropapillary & Pos & $\mathrm{HP}$ & Pos & $\mathrm{HP}$ \\
\hline & Mucinous & n.d. & n.d. & n.d. & n.d. \\
\hline \multirow[t]{2}{*}{1111} & Acinar & $\mathrm{Neg}$ & Tris & Pos & Amp \\
\hline & Lepidic/BA & n.d. & n.d. & n.d. & n.d. \\
\hline \multirow[t]{3}{*}{121212} & Solid & Pos & Amp & Neg & Tris \\
\hline & Acinar & Pos & Amp & Neg & Tris \\
\hline & Micropapillary & Pos & Amp & Neg & Tris \\
\hline \multirow[t]{3}{*}{141414} & Papillary & Pos & Amp & Pos & $\mathrm{HP}$ \\
\hline & Acinar & Pos & Amp & Pos & $\mathrm{HP}$ \\
\hline & Lepidic/BA & n.d. & n.d. & n.d. & n.d. \\
\hline \multirow[t]{2}{*}{1919} & Micropapillary & Pos & $\mathrm{HP}$ & Neg & Tris \\
\hline & Acinar & Pos & $\mathrm{HP}$ & Neg & Tris \\
\hline \multirow[t]{3}{*}{202020} & Lepidic/BA & Pos & $\mathrm{HP}$ & Neg & Tris \\
\hline & Acinar & Pos & $\mathrm{HP}$ & Neg & Tris \\
\hline & Micropapillary & n.d. & n.d. & n.d. & n.d. \\
\hline \multirow[t]{3}{*}{232323} & Lepidic/BA & Pos & $\mathrm{HP}$ & Pos & $\mathrm{HP}$ \\
\hline & Acinar & Pos & $\mathrm{HP}$ & Pos & $\mathrm{HP}$ \\
\hline & Mucinous & n.d. & n.d. & n.d. & n.d. \\
\hline \multirow[t]{3}{*}{262626} & Acinar & Neg & Tris & Pos & $\mathrm{HP}$ \\
\hline & Solid & Neg & Dis & Pos & $\mathrm{HP}$ \\
\hline & Lepidic/BA & n.d. & n.d. & n.d. & n.d. \\
\hline \multirow[t]{2}{*}{2727} & Solid & Pos & HP & Pos & $\mathrm{HP}$ \\
\hline & Lepidic/BA & n.d. & n.d. & n.d. & n.d. \\
\hline \multirow[t]{2}{*}{3030} & Lepidic/BA & Pos & $\mathrm{HP}$ & Pos & $\mathrm{HP}$ \\
\hline & Acinar & Pos & $\mathrm{HP}$ & Pos & $\mathrm{HP}$ \\
\hline
\end{tabular}

Estrat. - Estratification for FISH results; DIS - Disomy; LP - Low polysomy; Tris - Trisomy; HP - High polysomy; AMP - Amplification; n.d. - not determined.

All morphological registered patterns comprising this series of lung adenocarcinomas expressed CK7 positivity, without differences $(p>0.05)$, and predominant negativity for CK20, like other series published in the literature. ${ }^{8,27,33,34}$ CK20 was expressed in 3 cases of primary lung adenocarcinoma, with expression of CK7 and TTF1.

Mucinous glandular pattern showed lower expression of CK7 than the other patterns and one mucinous pattern had CK20 1+ expression in 10\% of the cells and 2 mixed adenocarcinomas showed $2+$ expression in $50 \%$ of the cells in both acinar and lepidic/BA patterns. At this point it is relevant to make a comment about the recently proposed classification for lung adenocarcinomas. ${ }^{8}$ This classification proposes the replacement of BA bronchiolo-alveolar pattern carcinoma designation for lepidic. When dealing with classical non-mucinous BAC, this histological type concerns TRU (terminal respiratory unit) cells, pool of adult stem cells in the lung where pneumocytes type II and Clara cells malignant counterparts are recognized; the proposed lepidic pattern seems to mean going for a morphologic description undervaluing carcinogenesis. Mucinous pulmonary adenocarcinoma cells exhibiting positivity for intestinal immunohistochemical markers, like CK20, MUC2 and COX2, fail to express TTF1 $^{35}$ and with bronchial origin may comprise either bronchial adenocarcinomas or intestinal type bronchial adenocarcinomas. At this point, the new proposed lung adenocarcinoma classification may contain a future relevant importance by gathering together all mucinous types of bronchial-pulmonary adenocarcinomas under the mucinous adenocarcinoma umbrella, eliminating the BAC mucinous type and again, giving life to BA pattern referring to the lepidic non-mucinous type. Predictive subtypes will be described to clarify origin and prognosis, between 
glandular and non-glandular mucinous bronchial-pulmonary adenocarcinomas. ${ }^{36}$

Also thyroid transcription factor-1 (TTF-1), tissuespecific transcriptional factor, identifies epithelial respiratory cells involved in the regulation of surfactant as pneumocytes type II and Clara cell secretory protein gene expression and distinguishes primary lung adenocarcinoma from metastasis of colorectal cancer. With the exception of papillary and solid patterns, all the other patterns had intense expression suggesting that some patterns showing decreased expression of TTF1 can explain a small number of cases developing in pure CK7 positive (bronchial) cells. ${ }^{27,28}$ It is a classical concern of pathologists to report a parameter related with tumour proliferation index and Ki67-MIB1 as a nuclear proliferation associated antigen expressed in cell cycle (G1,S,G2 and $M$ ) but not in the resting phase, $\mathrm{G} 0$, which provides information about the portion of active cells in the cell cycle. ${ }^{37,38} \mathrm{Ki}-67$ expression by immunohistochemistry can be a prognostic marker allowing the prediction of post-operative survival in different types of cancer. High expression of Ki-67 (cut-off above 10 ) is associated with worse survival in adenocarcinomas. ${ }^{30}$ Solid pattern expressed higher levels of Ki-67 when compared to micropapillary $(p=0.0219)$, acinar $(p=0.0731)$ and mucinous $(p=0.068)$ patterns and we can hypothesize that solid pattern can have a worse biological behaviour, either reflecting an higher proliferation index or a particular differential origin or as already referred, bronchial development when without expression of either TTF1 and high weight molecular cytokeratin (CK 5, 6/CK5, 6, 18).

Membrane expression of $\mathrm{C}$-erbB-2 as observed in breast carcinomas is absent in lung adenocarcinomas and has been reported as cytoplasmatic since early 90 s, in all morphological patterns. Solid pattern showed lower expression than acinar, papillary and micropapillary patterns raising again a question of prediction and specific genetic pathways worth exploring.

In the literature, there are numerous references for immunohistochemistry and genetic studies in lung adenocarcinomas and especially under the old nomenclature of NSCLC. The importance of this work lies in the fact that we compared IHC expression between the different patterns of lung adenocarcinomas to identify differences and relevance between them, pioneering the searching of EGFR and KRAS mutations together with EGFR and HER2 copy number also in between the different morphological patterns of lung adenocarcinomas.

In the submitted population we did not find correlations between age and mutation status, namely for EGFR and KRAS mutations. However EGFR mutations were more frequent in women and KRAS mutations in men. Gender and smoking habits have been significantly related with EGFR mutations. $^{2,3,30,39}$

The commonly reported EGFR mutation rate by PCR sequencing and fragment analyses in lung adenocarcinomas is around $20 \% .{ }^{40}$ Mutations are found in the first four exons of the TK domain of the EGFR gene. Short-mutations, in-frame deletions in exon 19 or point mutations resulting in a substitution of arginine for leucine at amino acid 858 (L858R), constitute roughly $90 \%$ of EGFR mutations ${ }^{4,41} ; 45 \%$ are exon 19 mutations, $41 \%$ are exon 21 mutations and the remaining $10 \%$ are exon 18 and 20 mutations (approximately 4\% of exon
18 and $5 \%$ of exon 20) - firstly described as more frequent in females, non-smokers, adenocarcinomas and Japanese patients. ${ }^{3,5,41}$ More than $70 \%$ of NSCLC with EGFR mutations are responsive to EGFR-TKIs while only $10 \%$ of tumours without EGFR mutations are responders. ${ }^{4}$

In our study, we had a rate of EGFR mutations of $46 \%$ gathering all patterns. Female patients had a $57.9 \%$ rate and male patients had a $27.3 \%$ rate ( 5 cases in 25$)(p=0.001)$. Female lung cancer patients have 6 times more risk (Odds Ratio $=6.286$ ) of having EGFR mutation than male patients. Shigematsu and Gazdar defined an EGFR superior mutational rate in women (49\%) than in male patients (19\%). A reference in this study is made to two other studies, based on Japanese subjects, where over $50 \%$ of female patients with lung cancer had higher expression of EGFR mutations. Although high, our EGFR mutation rate is not unique. It may reflect the exhaustive sampling covering all the patterns present, population features, and the selected population may have more advanced surgical cases. Tumour heterogeneity and genetic instability (leading to the accumulation of genetic events) could explain the EGFR mutation rate observed as well as the presence of different mutations.

We also tried to find the same relationship for the isolated mutations in exons 19 and 21. For exon 19, female patients had a rate of $52.6 \%$ (10 in a total of 19 females) while male patients had a rate of $0 \%$ ( 0 in a total of 11 males), $(p=0.000)$. For EGFR exon 21 , we found no significant differences $(p=0.835)$ between female and male patients as female lung cancer had a mutation rate of $26.3 \%$ while male patients had a rate of $27.3 \%$. Also, EGFR exon 21 mutations were however more frequent in women than in men.

EGFR mutations were described as more frequent in never smokers and the same was true in our study where $p=0.004$ (EGFR mutation was present in $60 \%$ of non-smokers and only in $23.1 \%$ of smokers). So, EGFR mutations are still associated with female gender and never smoking status. Despite EGFR mutations being more prevalent in nonsmokers we cannot be sure that smoking can prevent EGFR mutations. These findings only suggest that carcinogens contained in tobacco smoke are probably not correlated with the presence of EGFR mutations which might be caused by another type of carcinogens than higher numbers' EGFR copies. ${ }^{42}$

Some consider that FISH EGFR and HER2 copy numbers may be used when DNA quantity is not sufficient for EGFR mutation search as they showed some degree of TKI responses. ${ }^{3,19,39,42-44}$

HER2 has strong kinase activity. ${ }^{3,12-14}$ Mutations also occur in the same region ( $3^{\prime}$ of the $\alpha C$-helix) in exon 20 just as EGFR in-frame duplications/insertions, present in a very small fraction of adenocarcinomas of non-smokers and females, (the same as EGFR mutations) ${ }^{10,19}$; the majority are insertion mutations in exon 20 and the existence of HER2 mutations confers resistance to EGFR-TKIs but make tumours sensitive to HER2 target therapies. ${ }^{3,10,19,45-47}$ In our study we did not find HER2 mutations, indicating lesser importance of HER2 in lung adenocarcinomas' carcinogenesis.

When comparing KRAS exon 2 mutations and gender, we found that male lung cancer had significantly more incidence of mutation than female cases $(p=0.000)$. Male patients had a rate of $45.5 \%$ ( 5 in 11 male patients) while female had a rate of $0 \%$ ( 0 in 19 female patients). Our findings are similar 
to Kim et al. study, who also realized that KRAS mutations are significantly related with smoking habits $(p=0.014)$ in a total rate of $30.8 \%$ in smokers while in non-smokers it was only $5.7 \% \cdot{ }^{30,42}$

KRAS mutations have been associated with mucinous differentiation, goblet cell, poor differentiation adenocarcinomas and with solid patterns. ${ }^{48-52}$ However in our cases we did find this mutation in acinar and lepidic patterns and in only one case with solid pattern. The lower number of poorly differentiated adenocarcinomas, mucinous and solid patterns could in part explain the lower KRAS mutation rate.

EGFR mutations and KRAS mutations have been described as mutually exclusive but we found 1 case of KRAS mutation simultaneously with EGFR mutation. So we conclude that although EGFR and KRAS mutations are generally mutually exclusive, in some cases they can coexist; this has also been described by other authors. ${ }^{11,46,53-57}$ The clinical, therapeutic and prognostic issues concerning this coexistence need to be understood.

Although many studies demonstrated that EGFR mutations are usually related with an amplification in EGFR locus, the relationship between EGFR mutations, gene copy number, and IHC expression is still unclear and without relationship in our study. ${ }^{40,42-44,58}$ We have demonstrated correlation between mutational EGFR status and FISH high copy number. We did not find any correlation with IHC, maybe because gene amplification was not the prevalent event but gene polysomy reflecting aneuploidy, a frequent genetic alteration identified in lung carcinomas.

Increased copy number of EGFR was present in $40 \%$ of our cases which is comparable to the $36 \%$ already demonstrated. In our study, EGFR mutations had 7 times more risk (Odds Ratio $=7.016$ ) of having EGFR FISH positive $(p=0.001)$ than EGFR wt. We conclude that EGFR mutations are concordant with an increased gene copy number by FISH $(k=0.4595)$ with a significant correlation coefficient $(r=0.5303 ; p=0.0026)$. This is relevant because, knowing that some patients having high EGFR gene copy number can benefit from TKI, we might consider, specially in cases where mutational studies are inconclusive, using this information in therapeutic decisions. ${ }^{43,44}$ Concordance of the EGFR gene copy number by FISH and protein expression by IHC was seen in 7 of 12 IHC-positive cases. ${ }^{44}$

Lepidic/BA non-mucinous pattern has been described as having mutations of EGFR more frequently. Comparing our five different patterns (lepidic/BA, acinar, papillary, solid and micropapillary), despite not having statistical significance, EGFR and KRAS mutations were higher for the acinar pattern with a rate of $42.9 \%$ and $17.9 \%$ respectively with no statistical significance between them, followed by the lepidic/BA pattern. If we aggregate lepidic/BA and acinar patterns, EGFR mutations are more frequent in these two patterns when compared to the other patterns all together $(p=0.008)$. Recently other authors showed that EGFR and KRAS mutations are more frequent in lung carcinoma with adenocarcinoma differentiation based on p63 and TTF1 expression, p63 expression being the most useful immunohistochemical marker since they did not find any mutation in tumours considered p63 positive. ${ }^{51}$ In our work we went further correlating the mutational status also with the histological patterns present. Generally, when a mutation is present it is present in all the histological patterns of the same adenocarcinoma (Tables 2-4). Biopsies, representing only a small portion of a tumour, can be used to determine EGFR and KRAS mutational status.

The conclusions referred to above are predictive and again raise the controversies explored in the proposed lung adenocarcinomas classification: a small biopsy with a carcinoma CK7 positive and TTF1 positive is an adenocarcinoma (CK 5,6,18 negative) and has to be submitted to KRAS mutation search in a male patient, when acinar, solid pattern and lepidic/BA (non-mucinous type) pattern are present and also to EGFR mutational search for TKIs prescription decision.

Also to summarize, some adenocarcinomas show CK20 positivity in mucinous patterns/subtypes and solid patterns show lower expression of nuclear TTF1 and higher expression of Ki67, reflecting probably a particular cell origin and more aggressive biological behaviour and have to be reported as lung adenocarcinomas, avoiding poorly differentiated carcinoma designation.

After this study, it seems that EGFR and KRAS mutational status can be determined in biopsies representing bronchial pulmonary carcinomas because when a mutation is present it is generally present in all the histological patterns, needing further equivalent studies supported by a practical immunohistochemical panel.

\section{Conclusions}

The differences identified between the adenocarcinoma patterns reinforce the necessity to carefully identify the patterns present with implications for diagnosis and pathogenic understanding. Correlation was found in between EGFR FISH results and mutational status. There are adenocarcinomas harbouring different EGFR mutations in different patterns. In general, EGFR mutation is present in all the patterns of the same adenocarcinoma reinforcing the possibility of mutational status determination in biopsies.

\section{Conflicts of interest}

The author has no conflicts of interest to declare.

\section{Ethical disclosures}

Protection of human and animal subjects: The authors declare that no experiments were performed on humans or animals for this study.

Confidentiality of data: The authors declare that they have followed the protocols of their work centre on the publication of patient data.

Right to privacy and informed consent: The authors declare that no patient data appear in this article.

\section{Authorship}

V.S. was responsible for drafting the manuscript, immunohistochemical interpretation, compilation of clinical data and results as well for the statistical workflow. L.C. was responsible for the orientation, corrections as well for immunohistochemical interpretation. C.R. was responsible for drafting of the manuscript, results interpretation and 
also for statistical works. M.S. carried out FISH assays and results interpretation. A.M.A. carried out the immunoassays and mutational evaluation.

\section{Acknowledgement}

\section{CIMAGO - Centro de Investigação em Meio Ambiente, Genética e Oncobiologia.}

\section{References}

1. Jemal A, Clegg LX, Ward E, et al. Annual report to the nation on the status of cancer, 1975-2001, with a special feature regarding survival. Cancer. 2004;101:3-27.

2. Kim YT, Kim TY, Lee DS, et al. Molecular changes of epidermal growth factor receptor (EGFR) and KRAS and their impact on the clinical outcomes in surgically resected adenocarcinoma of the lung. Lung Cancer. 2008;59:111-8.

3. Shigematsu H, Gazdar AF. Somatic mutations of epidermal growth factor receptor signaling pathway in lung cancers. Int J Cancer. 2006;118:257-62.

4. Uramoto H, Mitsudomi T. Which biomarker predicts benefit from EGFR-TKI treatment for patients with lung cancer? Br J Cancer. 2007;96:857-63.

5. Sharma SV, Bell DW, Settleman J, et al. Epidermal growth factor receptor mutations in lung cancer. Nat Rev Cancer. 2007;7:169-81.

6. Travis W.D., Brambilla E, Müller-Hermelink HK, Harris CC. Pathology genetics of tumours of the lung, pleura, thymus and heart. Lyon: IARC Press; 2004.

7. Stahel RA. Adenocarcinoma, a molecular perspective. Ann Oncol. 2007;18 Suppl. 9:ix147-9.

8. Travis WD, Brambilla E, Noguchi M, et al. International association for the study of lung cancer/American Thoracic Society/European Respiratory Society International Multidisciplinary Classification of lung adenocarcinoma. J Thorac Oncol. 2011;6:244-85.

9. Gazdar AF. Activating and resistance mutations of EGFR in nonsmall-cell lung cancer: role in clinical response to EGFR tyrosine kinase inhibitors. Oncogene. 2009;28 Suppl. 1:S24-31.

10. Mitsudomi T, Yatabe Y. Mutations of the epidermal growth factor receptor gene and related genes as determinants of epidermal growth factor receptor tyrosine kinase inhibitors sensitivity in lung cancer. Cancer Sci. 2007;98:1817-24.

11. Eberhard DA, Johnson BE, Amler LC, et al. Mutations in the epidermal growth factor receptor and in KRAS are predictive and prognostic indicators in patients with non-small-cell lung cancer treated with chemotherapy alone and in combination with erlotinib. J Clin Oncol. 2005;23:5900-9.

12. Herbst RS, Fukuoka M, Baselga J. Gefitinib-a novel targeted approach to treating cancer. Nat Rev Cancer. 2004;4:956-65.

13. Linardou H, Dahabreh IJ, Kanaloupiti D, et al. Assessment of somatic k-RAS mutations as a mechanism associated with resistance to EGFR-targeted agents: a systematic review and meta-analysis of studies in advanced non-small-cell lung cancer and metastatic colorectal cancer. Lancet Oncol. 2008;9:962-72.

14. Normanno N, De Luca A, Bianco C, et al. Epidermal growth factor receptor (EGFR) signaling in cancer. Gene. 2006;366:2-16.

15. Rodenhuis S, van de Wetering ML, Mooi WJ, et al. Mutational activation of the K-ras oncogene. A possible pathogenetic factor in adenocarcinoma of the lung. N Engl J Med. 1987;317:929-35.

16. Suda K, Tomizawa K, Mitsudomi T. Biological and clinical significance of KRAS mutations in lung cancer: an oncogenic driver that contrasts with EGFR mutation. Cancer Metastasis Rev. 2010;29:49-60.
17. Kosaka T, Yatabe $\mathrm{Y}$, Endoh $\mathrm{H}$, et al. Mutations of the epidermal growth factor receptor gene in lung cancer: biological and clinical implications. Cancer Res. 2004;64:8919-23.

18. Shigematsu H, Lin L, Takahashi T, et al. Clinical and biological features associated with epidermal growth factor receptor gene mutations in lung cancers. J Natl Cancer Inst. 2005;97:339-46.

19. Shigematsu H, Takahashi T, Nomura M, et al. Somatic mutations of the HER2 kinase domain in lung adenocarcinomas. Cancer Res. 2005;65:1642-6.

20. Endoh H, Yatabe Y, Kosaka T, et al. PTEN and PIK3CA expression is associated with prolonged survival after gefitinib treatment in EGFR-mutated lung cancer patients. J Thorac Oncol. 2006;1:629-34.

21. Varella-Garcia M, Diebold J, Eberhard DA, et al. EGFR fluorescence in situ hybridisation assay: guidelines for application to non-small-cell lung cancer. J Clin Pathol. 2009;62: 970-7.

22. Inoue A, Suzuki T, Fukuhara T, et al. Prospective phase II study of gefitinib for chemotherapy-naive patients with advanced nonsmall-cell lung cancer with epidermal growth factor receptor gene mutations. J Clin Oncol. 2006;24:3340-6.

23. Yoshida K, Yatabe Y, Park JY, et al. Prospective validation for prediction of gefitinib sensitivity by epidermal growth factor receptor gene mutation in patients with non-small cell lung cancer. J Thorac Oncol. 2007;2:22-8.

24. Heatley M, Maxwell P, Whiteside C, et al. Cytokeratin intermediate filament expression in benign and malignant breast disease. J Clin Pathol. 1995;48:26-32.

25. Obermuller S, Calegari F, King A, et al. Defective secretion of islet hormones in chromogranin-B deficient mice. PLOS ONE. 2010;5:e8936.

26. Pelosi G, Pasini F, Sonzogni A, et al. Prognostic implications of neuroendocrine differentiation and hormone production in patients with Stage I nonsmall cell lung carcinoma. Cancer. 2003;97:2487-97.

27. Ikeda S, Fujimori M, Shibata S, et al. Combined immunohistochemistry of beta-catenin, cytokeratin 7 , and cytokeratin 20 is useful in discriminating primary lung adenocarcinomas from metastatic colorectal cancer. BMC Cancer. 2006;6:31.

28. Kubba LA, McCluggage WG, Liu J, et al. Thyroid transcription factor-1 expression in ovarian epithelial neoplasms. Mod Pathol. 2008;21:485-90.

29. Leech SN, Kolar AJ, Barrett PD, et al. Merkel cell carcinoma can be distinguished from metastatic small cell carcinoma using antibodies to cytokeratin 20 and thyroid transcription factor 1 . J Clin Pathol. 2001;54:727-9.

30. Woo T, Okudela K, Yazawa T, et al. Prognostic value of KRAS mutations and $\mathrm{Ki}-67$ expression in stage I lung adenocarcinomas. Lung Cancer. 2009;65:355-62.

31. Ikeda S, Fujimori M, Shibata S, et al. Combined immunohistochemistry of beta-catenin, cytokeratin 7 , and cytokeratin 20 is useful in discriminating primary lung adenocarcinomas from metastatic colorectal cancer. BMC Cancer. 2006;2:6.

32. Sousa V, Espirito Santo J, Silva M, et al. EGFR/erB-1, HER2/erB2, CK7, LP34, Ki67 and P53 expression in preneoplastic lesions of bronchial epithelium: an immunohistochemical and genetic study. Virchows Arch. 2011;458:571-81.

33. Tsao SC, Su YC, Wang SL, et al. Use of caveolin-1, thyroid transcription factor-1, and cytokeratins 7 and 20 in discriminating between primary and secondary pulmonary adenocarcinoma from breast or colonic origin. Kaohsiung J Med Sci. 2007;23:325-31.

34. Su YC, Hsu YC, Chai CY. Role of TTF-1, CK20, and CK7 immunohistochemistry for diagnosis of primary and secondary lung adenocarcinoma. Kaohsiung J Med Sci. 2006;22:14-9.

35. Tsuta K, Ishii G, Yoh K, et al. Primary lung carcinoma with signetring cell carcinoma components: clinicopathological analysis of 39 cases. Am J Surg Pathol. 2004;28:868-74. 
36. Rossi G, Murer B, Cavazza A, et al. Primary mucinous (socalled colloid) carcinomas of the lung: a clinicopathologic and immunohistochemical study with special reference to CDX2 homeobox gene and MUC2 expression. Am J Surg Pathol. 2004;28:442-52.

37. Neves LR, Oshima CT, Artigiani-Neto R, et al. Ki67 and p53 in gastrointestinal stromal tumours-GIST. Arq Gastroenterol. 2009;46:116-20.

38. Scholzen T, Gerdes J. The Ki-67 protein: from the known and the unknown. J Cell Physiol. 2000;182:311-22.

39. Gazdar AF. Activating and resistance mutations of EGFR in nonsmall-cell lung cancer: role in clinical response to EGFR tyrosine kinase inhibitors. Oncogene. 2009;28:24-31.

40. El-Zammar OA, Zhang S, Katzenstein AL. Comparison of FISH, $\mathrm{PCR}$, and immunohistochemistry in assessing EGFR status in lung adenocarcinoma and correlation with clinicopathologic features. Diagn Mol Pathol. 2009;18:133-7.

41. Mitsudomi T, Kosaka T, Yatabe Y. Biological and clinical implications of EGFR mutations in lung cancer. Int J Clin Oncol. 2006;11:190-8.

42. Mitsudomi T, Yatabe Y. Mutations of the epidermal growth factor receptor gene and related genes as determinants of epidermal growth factor receptor tyrosine kinase inhibitors sensivity in lung cancer. Cancer Sci. 2007;98:1817-24.

43. Amann J, Kalyankrishna S, Massion PP, et al. Aberrant epidermal growth factor receptor signaling and enhanced sensitivity to EGFR inhibitors in lung cancer. Cancer Res. 2005;65:226-35.

44. Takano T, Ohe Y, Sakamoto H, et al. Epidermal growth factor receptor gene mutations and increased copy numbers predict gefitinib sensitivity in patients with recurrent non-small-cell lung cancer. J Clin Oncol. 2005;23:6829-37.

45. Cappuzzo F, Bemis L, Varella-Garcia M. HER2 mutation and response to trastuzumab therapy in non-small-cell lung cancer. N Engl J Med. 2006;354:2619-21.

46. Han SW, Kim TY, Jeon YK, et al. Optimization of patient selection for gefitinib in non-small cell lung cancer by combined analysis of epidermal growth factor receptor mutation, K-ras mutation, and Akt phosphorylation. Clin Cancer Res. 2006;12: 2538-44.

47. Wang SE, Narasanna A, Perez-Torres M, et al. HER2 kinase domain mutation results in constitutive phosphorylation and activation of HER2 and EGFR and resistance to EGFR tyrosine kinase inhibitors. Cancer Cell. 2006;10:25-38.
48. Finberg KE, Sequist LV, Joshi VA, et al. Mucinous differentiation correlates with absence of EGFR mutation and presence of KRAS mutation in lung adenocarcinomas with bronchioloalveolar features. J Mol Diagn. 2007;9:320-6.

49. Kobayashi T, Tsuda $H$, Noguchi $M$, et al. Association of point mutation in $\mathrm{c}-\mathrm{Ki}$-ras oncogene in lung adenocarcinoma with particular reference to cytologic subtypes. Cancer. 1990;66:289-94.

50. Marchetti A, Buttitta F, Pellegrini S, et al. Bronchioloalveolar lung carcinomas: K-ras mutations are constant events in the mucinous subtype. J Pathol. 1996;179:254-9.

51. Sakuma Y, Matsukuma S, Yoshihara M, et al. Distinctive evaluation of nonmucinous and mucinous subtypes of bronchioloalveolar carcinomas in EGFR and K-ras gene-mutation analyses for Japanese lung adenocarcinomas: confirmation of the correlations with histologic subtypes and gene mutations. Am J Clin Pathol. 2007;128:100-8.

52. Yatabe Y, Koga T, Mitsudomi T, et al. CK20 expression, CDX2 expression, K-ras mutation, and goblet cell morphology in a subset of lung adenocarcinomas. J Pathol. 2004;203:645-52.

53. Pao W, Wang TY, Riely GJ, et al. KRAS mutations and primary resistance of lung adenocarcinomas to gefitinib or erlotinib. PLoS Med. 2005;2:e17.

54. Gumerlock PH, Holland WS, Chen H, et al. Mutational analysis of K-RAS and EGFR implicates K-RAS as a resitance marker in the Southwest Oncology Group (SWOG) trial S0126 of bronchioalveolar carcinoma (BAC) patients (pts) treated with gefitinib. J Clin Oncol. 2005;23:623s (suppl; abstr 7008).

55. Modjtahedi H, Essapen S. Epidermal growth factor receptor inhibitors in cancer treatment: advances, challenges and opportunities. Anticancer Drugs. 2009;20:851-5.

56. Tam IY, Chung LP, Suen WS, et al. Distinct epidermal growth factor receptor and KRAS mutation patterns in non-small cell lung cancer patients with different tobacco exposure and clinicopathologic features. Clin Cancer Res. 2006;12:1647-53.

57. Zhu CQ, da Cunha Santos G, Ding K, et al. Role of KRAS and EGFR as biomarkers of response to erlotinib in National Cancer Institute of Canada Clinical Trials Group Study BR.21. J Clin Oncol. 2008;26:4268-75.

58. Li AR, Chitale D, Riely GJ, et al. EGFR mutations in lung adenocarcinomas: clinical testing experience and relationship to EGFR gene copy number and immunohistochemical expression. J Mol Diagn. 2008;10:242-8. 